\title{
O CONTRATO SOCIAL NAS SOCIEDADES LIMITADAS
}

Camila Cortes do Carmo, Renan Fontolan Sampaio, Sandra Cristina Pelegrini Giacomelli, Pedro Teófilo de Sá

Universidade do Oeste Paulista - UNOESTE. Curso de Ciências Contábeis, Presidente Prudente - SP. E-mail: mila_camyyla@hotmail.com

\section{RESUMO}

O objetivo deste artigo é analisar a cláusula de administração da Sociedade Limitada, verificando a responsabilidade do Sócio Administrador. A fase de constituição da sociedade limitada é de grande importância, pois é neste momento que todos os direitos e deveres dos sócios deverão ser explicitados. Deverá constar a cláusula de administração, que poderá ser singular ou colegiada, inclusive com a indicação do administrador e seus poderes. Os atos de gestão não poderão ferir a lei, ao contrato social, ou serem praticados com abuso de poder, pois se assim ocorrer, o administrador responderá pessoalmente pelos prejuízos causados à sociedade, conforme determinação do Código Civil e do Código Tributário Nacional.

Palavras-chave: Sociedade Limitada - Contrato Social - Administrador

\section{SOCIAL CONTRACT IN COMPANIES LIMITED}

\begin{abstract}
The purpose of this article is to analyze the provision of administration of the Limited Partnership, checking the responsibility of the Managing Partner. The phase constitution of limited partnership is of great importance because it is at this point that all the rights and duties of the partners should be explained. Should include the provision of administration, which may be natural or collegiate, including the appointment of the administrator and his powers. Management actions will not hurt the law, the social contract, or be charged with abuse of power, because if they occur, the administrator personally liable for damages caused to society, as determined by the Civil Code and the tax code.
\end{abstract}

Keywords: Private Limited Company - Social Contract - Manager 


\section{INTRODUÇÃO E OBJETIVO}

Como em qualquer outro lugar do planeta, em nosso país existem milhões de pessoas interessadas em uma melhoria independente e particular de vida, de emprego, poder aquisitivo, dentre outras. Muitas vezes, se arriscam adentrando no mundo empresarial. E, alguns optam por criar empresas em conjunto com outros empresários, dividindo as responsabilidades e os lucros do negócio em questão.

Essa aglutinação de esforços com diversos, ou alguns, empreendedores é chamado de sociedade, cujos tipos mais comuns são Sociedade Anônima e a Sociedade Limitada. A Sociedade Anônima possui capital social divido em ações e a responsabilidade os sócios limita-se ao valor das ações subscritas. A Sociedade Limitada é a sociedade onde o capital social é representado por quotas, e a responsabilidade dos sócios é limitada ao montante do capital social investido.

Segundo Coelho (2012, p.185), a Sociedade Limitada é o tipo societário mais presente em nossa economia, e esse sucesso é devido às suas duas principais características, que são a limitação da responsabilidade dos sócios e a contratualidade.

Negrão (2012, p.390) define que a Sociedade Limitada é baseada na solidariedade entre os sócios, porém, somente no caso de algum deles não integralizar sua parcela do capital social. É de extrema importância explicitar no contrato os detalhes específicos, pois é a partir deste documento que a empresa irá buscar a personalidade jurídica para poder atuar no mercado como sociedade de direito.

Devido à limitação da responsabilidade dos sócios, mostra-se importante estudar a formação do contrato social, objetivando a análise da cláusula de administração, destacando a responsabilidade do sócio administrador a fim de se saber se ele poderá responder pessoalmente pelos atos de administração.

A importância do estudo justifica-se pelo fato de que, nos muitos investimentos em negócios, há preocupações em conseguir espaço no mercado buscando a lucratividade. Porém, não é simples assim construir uma empresa, e trilhar um caminho de sucesso, visto que, antes do início das atividades é necessário constituir o chamado contrato social, definir os sócios, o sócio administrador da sociedade, o valor do capital, dentre outras cláusulas.

O presente artigo tem como objetivo analisar a cláusula de administração da Sociedade Limitada, estudando a responsabilidade do Sócio Administrador, a fim de contribuir com a informação aos empresários e ao meio social, para que conheçam os aspectos contratuais e seus desdobramentos, a fim de que possam permanecer no mercado fomentando o crescimento econômico empresarial. 


\section{METODOLOGIA}

O presente trabalho se baseia em uma abordagem qualitativa, pautada em pesquisa bibliográfica exploratória apoiada em doutrinas, revistas especializadas, artigos científicos, sites jurídicos, dentre outros.

\section{RESULTADOS}

Após realização do presente trabalho, foi possível confirmar a importância de formalizar um contrato social, com atenção especial para a cláusula de indicação da administração, inclusive nomeando o sócio ou os sócios para o exercício do cargo. Tal administração deverá se pautada na lei e no contrato social, a fim de que sirva de norte ao administrador na prática dos seus atos de gestão. Isto porque os atos de gestão poderão levar à responsabilização pessoal do seu administrador, quando praticados com desrespeito à lei, ao contrato ou com abuso de poder.

\section{DISCUSSÃO}

Primeiramente, antes de discorrer sobre Sociedade Empresarial, cabe esclarecer que etimologicamente a palavra Sociedade vem do latim, significando societas, cuja significação é associação amistosa com outros. É ainda, um conjunto de seres que convivem de formar organizada e compartilham propósitos, gostos e preocupações. Nesse caso, tudo que um indivíduo não consiga atingir ou conquistar, agindo sozinho, pode conseguir através de uma união, com isso, a sociedade tem grande importância tanto no mundo civil, quanto no mundo comercial. (MURTA, 2001, p. 05)

As sociedades comerciais nascem da união de pessoas que somam esforços e bens para a prática de atos de natureza comercial, com a intenção de gerar lucros. Segundo Requião (2011, p. 426), celebram contrato de sociedade, as pessoas que se obrigam a contribuir com bens ou serviços, no exercício de atividade econômica e dividem os resultados.

Nos dias atuais, as sociedades mais comuns no meio empresarial são a Sociedade Anônima e a Sociedade Limitada. Naquela, o capital social de uma será dividido em ações e os sócios possuem responsabilidades limitadas ao valor das ações subscritas, ao passo que, nesta o capital social será representado por quotas e os sócios possuem responsabilidade limitada ao montante do capital social investido, podendo haver responsabilidade solidária entre os sócios, no caso de não integralização de parcela do capital social.

A Sociedade Limitada surgiu na Inglaterra, em meados do século XIX, decorrente da expansão comercial ocorrida pela Revolução Industrial, fato que proporcionou um limite na 
responsabilidade dos pequenos e médios comerciantes, como forma de fugir das regras formais da Sociedade Anônima. (CARVALHOSA, 2005, p. 01)

No mesmo sentido encontra-se o posicionamento de Requião (2011, p. 539), esclarecendo que desde 1857 já estava regulado um tipo de sociedade, denominada limited by guarante, na qual os sócios respondiam até o montante do capital social descrito no contrato. Esclarece ainda que, no Brasil, a sociedade limitada foi introduzida em 1912, pelo projeto do professor Herculano Inglez de Souza.

Trata-se do tipo de sociedade mais utilizado entre os empresários brasileiros, supostamente devido à responsabilidade limitada dos sócios e a facilidade da constituição do contrato.

Em suma, é uma sociedade que realiza atividade empresarial, formada por dois ou mais sócios, que contribuem com moeda ou bens materiais avaliáveis em dinheiro para a formação do seu capital social, e os sócios possuem responsabilidade restrita no valor de suas quotas, mas todos podem responder solidariamente pela integralização do capital social, conforme determina o art. 1.052 do Código Civil.

Na Sociedade Limitada, a responsabilidade dos sócios está sujeita a limites. Esse limite é o total do capital social que foi subscrito, mas se não integralizado todos devem responder solidariamente pela integralização. (COELHO, 2012, p. 189)

Pela regra de solidariedade caso não tenha havido a integralização do capital social, e caso a sociedade tenha contraído dívidas e não possua patrimônio suficiente para quitação dos débitos, os sócios deverão integralizar a parte faltante do capital social (CARVALHOSA, 2005, p. 13). Mas, caso o capital social esteja totalmente integralizado, o patrimônio pessoal dos sócios não responde por dívidas da sociedade. (COELHO, 2013, p. 188)

A responsabilidade dos sócios é limitada ao valor das quotas que subescreveu, porém, o Código Civil de 2002 prevê exceções para a limitação da responsabilidade quando ocorrer atos lesivos praticados a terceiros, aos sócios ou à sociedade, passando a responder ilimitadamente pelas obrigações contraídas.

A formação da sociedade se dá pela manifestação escrita, da vontade de duas ou mais pessoas, que unirão seus esforços para uma atividade em comum, formalizada por meio de contrato social escrito, por instrumento público ou particular, que deverá ser levado a registo para aquisição da personalidade jurídica. (CARVALHOSA, 2005, p. 54) 
Assim, é importante destacar que uma das principais finalidades do registro ou arquivamento do contrato social, é para torná-lo público de modo que terceiros possam conhecer o seu teor, dando segurança jurídica dos atos praticados pela sociedade.

Como se vê, o Contrato Social é a ferramenta principal utilizada para que uma sociedade seja constituída. Ele é o documento que materializa as regras básicas da sociedade apresentando as normas de constituição e funcionamento da sociedade.

Para Coelho (2012, p.160), o contrato social contém a vontade conjunta de exploração de determinada atividade comercial, reunindo de esforços para obtenção de lucros, que serão repartidos entre os sócios. Em resumo, ele é um documento que estabelece todas as normas de relacionamento entre os sócios e a sociedade.

A Cláusula de administração da sociedade limitada deverá especificar a quem caberá tal cargo, o de responsável pelo seu gerenciamento, que deverá constará no contrato social. Segundo Requião (2011, p. 585) o cargo de administrador poderá ser exercido por um sócio, ou por vários. Sendo singular ou colegiado exercício da administração, ela servirá para a representatividade da sociedade.

Apenas pessoas físicas podem fazer parte da administração de uma sociedade limitada, pois além de praticarem atos físicos, deverão exercer certa compreensão da realidade e expressão de sua vontade, que fará em nome da sociedade que representa. (MAMEDE, 2013, p. 102)

De acordo com Carvalhosa (2005, p. 103) o Código Civil de 2002 permite que a administração da sociedade seja exercida por terceiros, ou seja, não sócios e regulamenta também como será o regime de investidura, término do cargo, destituição, renúncia, exercício de atividade e prestação de contas, estabelecendo uma estrutura organizada para a sociedade limitada.

Em continuidade de raciocínio adverte Mamede (2013, p.103) que o representante da sociedade limitada, o administrador, será obrigado a prestar contas de sua atuação, podendo ser fiscalizado pelos demais sócios, de acordo com as determinações do contrato social.

Logo, uma sociedade limitada poderá ser administrada por uma ou mais pessoas, (sócios ou não sócios), desde que designadas no contrato social ou em ato separado, podendo ser prorrogada a sua duração, de acordo com a determinação contratual. (CARVALHOSA, 2005, p. 122)

Em decorrência da administração os administradores da sociedade limitada, em regra, não respondem pelas obrigações da sociedade, desde que, praticados atos regulares, pois os mesmos não agem em seu nome e sim em nome da sociedade que representam, devendo agir com cuidado e zelo, conforme determina o art. 1.011 do Código Civil. 
Os atos do administrador, além de expressar a realidade contratual e seus limites impostos, deverão respeitar a vontade da maioria, sob a pena de responder por perdas e danos na forma do parágrafo segundo do art. 1.013, desde que tenha agido com culpa, caso em que responderá solidariamente perante a sociedade e a terceiros, conforme determina o art. 1.016, também do Código Civil.

Para Carvalhosa (2005, p. 138) os atos de administração praticados em desacordo com a legislação vigente, o contrato social, ou que representem abusos de poderes ou desvios de finalidades, causando prejuízo à sociedade ou a terceiros, implicam em violação de poderes da gestão e serão de responsabilidade pessoal do administrador.

Desta forma, responderá o administrador, pessoalmente, pelos créditos referentes a obrigações tributárias decorrentes de atos praticados com excesso de poderes ou infração de lei, contrato social ou estatuo, conforme determina o art. 135 do Código Tributário Nacional.

A responsabilidade pelos atos praticados na gestão só termina mediante aprovação das contas do administrador na assembléia geral ou reunião dos sócios. (CARVALHOSA, 2005, p. 127),

Entretanto a responsabilidade pessoal do sócio subsistirá quando se tratar de atos de administração que resultem de fraude ou abuso, que não são possíveis verificar na prestação de contas, permanecem sob a responsabilidade civil e criminal do administrador. (CARVALHOSA, 2005, p. 146)

\section{CONCLUSÕES}

É inquestionável a contribuição das sociedades empresariais para o mundo contemporâneo, tanto na circulação de riquezas quanto na observância do respeito às regras de administração.

A elaboração do contrato social deve contemplar a cláusula de administração, prevendo que ela possa ser desenvolvida por um sócio, ou por vários, em conjunto, ou separadamente. Tal cláusula deverá representar o norte para a sociedade e para os sócios, devendo espelhar a realidade social de modo a limitar a atuação da gestão.

Com isto, é certo que a cláusula de administração da Sociedade Limitada, deve enfatizar a responsabilidade da administração, fato que demonstra a importância da formalização de um contrato social que atenda aos anseios sociais, e deixe claras as responsabilidades do sócio administrador para o bom funcionamento da sociedade e da sua convivência harmoniosa os sócios e os administradores. 
Os administradores devem submeter-se às regras previstas nas cláusulas do contrato social e na legislação específica, observando que a pratica de atos com ferimento à lei, ao contrato, ou com abuso de poder poderão render ao administrador a responsabilidade pessoal pelos danos causados à sociedade.

Conclui-se que, atenção especial merece a cláusula da administração, pois caberá ao administrador todo o gerenciamento da sociedade, bem como a responsabilidade solidária pelos atos praticados, de modo que, todo ato do administrador contrário ao contrato social, é de inteira responsabilidade do mesmo, devendo ele suportar as consequências.

O contrato social é a cartilha que, tanto os sócios, quanto o administrador ou administradores, deverão seguir criteriosamente, para isso, o mesmo deverá estar de acordo com as normas vigentes. Dessa forma, a sociedade limitada deve possuir um Contrato Social claro e objetivo, com cláusulas que poderão servir de norte à sociedade e, também, de alicerce para qualquer dúvida ou problema que possa surgir durante o exercício social.

\section{REFERÊNCIAS}

CARVALHOSA, M.; Comentários ao Código Civil: Parte Especial do Direito de Empresa. 2a Ed. São Paulo, Editora Saraiva, 2005.

COELHO, F. U; Manual de Direito Comercial: Direito de Empresa. 24a Ed. São Paulo, Editora Saraiva, 2012.

; Manual de Direito Comercial: Direito de Empresa. 25ạ Ed. São Paulo, Editora Saraiva, 2013.

MAMEDE, Gladston; Manual de Direito Empresarial, 7ạ Ed., São Paulo, Ed. Atlas, 2013.

MURTA, A. C. D.; Responsabilidade Tributária dos Sócios: Sociedades por Quotas de Responsabilidade Limitada. 1a Ed. Belo Horizonte, Livraria Del Rey, 2001.

NEGRÃO, F.; Manual de Direito Comercial e de Empresa: Teoria Geral da Empresa e Direito Societário. 9ạ Ed. São Paulo, Editora Saraiva, 2012.

REQUIÃO, R.; Curso de Direito Comercial, 1ำ volume. 30a Ed. São Paulo, Editora Saraiva, 2011.

<http://www.fastjob.com.br/consultoria/artigos_visualizar_ok_todos.asp?cd_artigo-=214> (Acesso em 18/06/2014). 